\title{
Fabrication of patterned thermoresponsive microgel strips on cell-adherent background and their application for cell sheet recovery
}

Dol:

10.1021/acsami.6b12762

\section{Document Version}

Accepted author manuscript

Link to publication record in Manchester Research Explorer

Citation for published version (APA):

Xia, Y., Tang, Y., Wu, H., Wang, S., Wang, X., Zhang, J., Li, Z., Pan, F., Xu, H., \& Lu, J. (2017). Fabrication of patterned thermoresponsive microgel strips on cell-adherent background and their application for cell sheet recovery. ACS Applied Materials and Interfaces, 9(2), 1255-1262. https://doi.org/10.1021/acsami.6b12762

\section{Published in:}

ACS Applied Materials and Interfaces

\section{Citing this paper}

Please note that where the full-text provided on Manchester Research Explorer is the Author Accepted Manuscript or Proof version this may differ from the final Published version. If citing, it is advised that you check and use the publisher's definitive version.

\section{General rights}

Copyright and moral rights for the publications made accessible in the Research Explorer are retained by the authors and/or other copyright owners and it is a condition of accessing publications that users recognise and abide by the legal requirements associated with these rights.

\section{Takedown policy}

If you believe that this document breaches copyright please refer to the University of Manchester's Takedown Procedures [http://man.ac.uk/04Y6Bo] or contact uml.scholarlycommunications@manchester.ac.uk providing relevant details, so we can investigate your claim.

\section{OPEN ACCESS}


Xia, Y.; Tang, Y.; Wu, H.; Zhang, J.; Li, Z.Y.; Pan, F.; Wang, S.J.; Wang, X.J.; Xu, H.;

Lu, J.R., ACS Appl. Mater. Interface 2017, 9, 1255-1262. DOI: 10.1021/acsami.6b12762

Fabrication of Patterned Thermoresponsive Microgel Strips on Cell-adherent

\section{Background and Their Application for Cell Sheet Recovery}

Yongqing Xia $*^{a}$, Ying Tang ${ }^{a}$, Han $W^{a}$, Jing Zhang ${ }^{b}$, Zongyi $L^{b}{ }^{b}$, Fang Pan $^{b}$, Shengjie Wang ${ }^{b}$, Xiaojuan Wang $^{a}$, Hai Xu $u^{a}$, Jian Ren Lu* ${ }^{b}$

${ }^{\text {a }}$ State Key Laboratory of Heavy Oil Processing and Centre for Bioengineering and Biotechnology, China University of Petroleum (East China), Qingdao 266580, China

\footnotetext{
${ }^{\mathrm{b}}$ Biological Physics Laboratory, School of Physics and Astronomy, University of Manchester, Schuster Building, Oxford Road, Manchester M13 9PL, United Kingdom
} 


\section{Abstract}

Interfaces between materials and cells play a critical role in cell biomedical applications. Here, a simple, robust and cost-effective method is developed to fabricate patterned thermoresponsive poly(N-isopropylacrylamide-co-styrene) (pNIPAAmSt) microgel strips on a PEI-precoated, non-thermoresponsive cell-adherent glass coverslip. The aim is to investigate whether cell sheets could be harvested from these cell-adherent surfaces patterned with thermoresponsive strips comprised of the microgels. We hypothesize that if the cell-to-cell interaction is strong enough to retain the whole cell sheet from disintegration, the cell segments growing on the thermoresponsive strips may drag the cell segments growing on the cell-adherent gaps to detach, ending up with a whole freestanding and transferable cell sheet. Critical value concerning the width of the thermoresponsive strip and its ratio to the non-thermoresponsive gap may exist for cell sheet recovery from this type of surface pattern. To obtain this critical value, a series of strip patterns with various widths of thermoresponsive strip and non-thermoresponsive gap were prepared using negative microcontact printing technology, with COS7 fibroblast cells being used to test the growth and detachment. The results unraveled that COS7 cells preferentially attached and proliferated on the cell-adherent, non-thermoresponsive gaps to form patterned cell layers and that they subsequently proliferated to cover the microgel strips to form a confluent cell layer. Intact COS7 cell sheets could be recovered when the width of the thermoresponsive strip is no smaller than that of the non-thermoresponsive gap. Other cells such as HeLa, NIH3T3, 293E and L929 could grow similarly, that is, they showed initial preference to the non-thermoresponsive gaps and then migrated to cover the entire patterned surface. However, it was difficult to detach them as cell sheets due to the weak interactions within the cell layers formed. In contrast, when COS7 and HeLa cells were cultured successively, they formed the co-cultured cell layer that could be detached together. These freestanding patterned cell sheets could lead to the development of more elaborate tumor models for drug targeting and interrogation.

\section{Keywords}

Biointerface, Functional interface, Micropatterning, Thermoresponsive microgels, Cell sheet harvesting, microgel strips, Thermoresponsive cell removal. 


\section{Introduction}

Interfaces dictate cell performance and play a critical role in many cell biomedical applications by controlling processes such as cell attachment, migration, orientation, critical adhesion and differentiation through delicate surface engineering. ${ }^{1-5}$ Among various engineered interfaces, the patterned surfaces in which adhesive islands located on a non-adhesive background have attracted much interest in recent years. Ingber et al pioneered cell spreading confinement on micropatterned surfaces and demonstrated the geometrical control of cell fates. ${ }^{6}$ They showed that adherent cells could be switched from growth to apoptosis by using micropatterned substrates containing extracellular matrix protein coated islands of decreasing size to restrict cell extension. They also demonstrated that cell spreading could be varied whilst keeping the total cell-matrix contact area constant by changing the gap distance between multiple focal adhesion-sized islands. By topographical modifications to the substrate surfaces, the shapes individual cells adopt could be manipulated, thereby resulting in fatal consequences of growth or death. Patterns on polymeric surfaces can be fabricated by soft lithography, photolithography and electron beam lithography. With well-defined surface patterns, the choice of polymers and surface film coating approaches have also enabled elaborate studies of the effects of surface chemical nature and morphological structures on the interactions between cells and the substrate during dynamic processes of cell adhesion, spreading and growth. ${ }^{7-9}$

Intact cell sheets could non-invasively detach from thermoresponsive platforms and maintain their cell-to-cell connections. These cell sheets could be used as $2 \mathrm{D}$ or $3 \mathrm{D}$ biomedical constructs or for tissue damage repair. ${ }^{10-14}$ Patterned thermosensitive coatings have recently been developed for cell detachment control, with several recent studies reporting their attractive benefits for cell sheet harvesting. ${ }^{15-18}$ Okano group prepared a micropatterned thermoresponsive surface which consisted of strip-like micropatterns of 
poly(N-isopropylacrylamide) (pNIPAAm) brush domains and poly( $\mathrm{N}$-isopropylacrylamide)-bpoly(N-acryloylmorpholine) domains using RAFT-mediated block copolymerization and photolithography. They showed that aligned cell clusters could be harvested as a tissue-like cellular monolayer from these patterned surfaces. ${ }^{15}$ The same group also prepared polyacrylamide (pAAm) patterns on a thermoresponsive pNIPAAm surface fabricated on a cell-repellent background, and the detachment of the adhered cells could be more rapidly achieved from the patterned surface after reducing temperature. ${ }^{18}$

Microcontact printing $(\mu \mathrm{CP})$ has been demonstrated as a technique for the delivery of micro-nanometer materials such as proteins, ${ }^{19} \mathrm{DNA},{ }^{20}$ bacteria,${ }^{21}$ colloids and others, ${ }^{22,23}$ as surface patterns onto a target substrate. A stamp (which is usually made of poly(dimethylsiloxane) (PDMS)) inked with the materials of interest is used to print onto the substrate surface, with the desired pattern formed. Compared with other microfabrication techniques such as photolithography and soft lithography, both of which are more elaborate to operate, it is easy to use $\mu \mathrm{CP}$ to fabricate micropatterned surfaces onto various backgrounds.

In this work, we aim to examine how the critical width of the thermoresponsive strip micropatterned on a cell-adherent non-thermoresponsive background affects the cell sheet to detach from the entire surface using the strategy of $\mu \mathrm{CP}$. To achieve this aim, a series of micropatterned surfaces with various widths of thermoresponsive strip and cell-adherent non-thermoresponsive background gap were prepared through $\mu \mathrm{CP}$, and COS7 cells were cultured on those patterned surfaces. Once confluent, their detachment behavior was examined by reducing temperature. Results showed that COS7 cells preferentially adhered within the cell-adherent gaps to form cell patterns. After these gaps were occupied, cells would migrate onto the microgel strips to form a confluent cell layer, but the cell sheet could then be harvested by thermally stimulating the expansion of the underlying thermoresponsive microgels without disrupting their patterns. Whether an intact cell sheet could be recovered or not depended not only on the design of the patterns, but also on cell types. COS7 cell sheets could be recovered when the width of the thermoresponsive strip is 
equal to or larger than that of the cell-adherent gap, but NIH3T3, HeLa and L929 cell sheets could not be recovered under the same conditions because these cells could not hold to each other tightly enough. However, when HeLa and COS7 cells were seeded on a patterned surface successively, a co-cultured cell sheet could be recovered due to the integrity of the COS7 cells in the patterned layer. This approach may provide a useful platform for harvesting patterned cell sheets for building elaborate tissue constructs, e.g., as in vitro tumor models.

\section{Experimental and materials}

\subsection{Materials}

All the chemicals were obtained from Sigma-Aldrich. N-isopropyl acrylamide (NIPAAm) was purified by recrystallization from a toluene/hexane mixture (1:3) and dried in vacuum. Styrene (St) was purified by distillation under reduced pressure, ammonium persulfate (APS) was purified by recrystallization from water. N, N'-methylene bisacrylamide (MBA) was used as received. The molecular weight of PEI is 750 $\mathrm{kDa}$. All water used in this experiment was processed by Milli-Q system (Milli-Q Advantage A10 Water System Production Unit). Cell culture plates (6-well plates, from Corning) were used as received. Glass coverslips $\left(20 \times 20 \mathrm{~mm}^{2}\right)$ were immersed into piranha solution $\left(\mathrm{H}_{2} \mathrm{O}_{2} / \mathrm{H}_{2} \mathrm{SO}_{4}=1: 3\right.$ by volume $)$ at $90{ }^{\circ} \mathrm{C}$ for 1 $\mathrm{h}$ to remove organic impurities, followed by abundantly rinsing with tap water and UHQ water, and dried by nitrogen purging. They were then immersed in $1 \mathrm{wt} \% \mathrm{PEI}$ solution $(\mathrm{pH}=5)$ before use.

PDMS stamps were commissioned from CapitalBio Corporation (China) and the smooth surface bear ridges with depth about $10 \mu \mathrm{m}$, and the widths of the ridges and gaps between them are 50,100, 200 and $500 \mu \mathrm{m}$, respectively. 


\section{2. pNIPAAmSt microgel preparation}

PNIPAAmSt microgels were prepared by surfactant-free precipitation polymerization as described in our

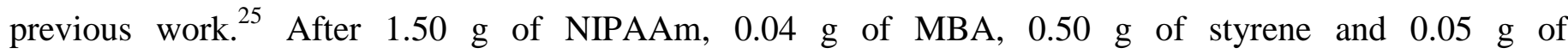
fluorescein-5-isothiocyanate (FITC-Na) were added in $190 \mathrm{~mL}$ of water, the reaction mixture was transferred to a four-necked round-bottom flask equipped with a condenser and a nitrogen inlet, and then heated to $70{ }^{\circ} \mathrm{C}$ under a gentle stream of nitrogen. After $1 \mathrm{~h}, 0.12 \mathrm{~g}$ of an initiator (APS) was dissolved in 10 $\mathrm{mL}$ of water (oxygen free) and added to the flask to initiate polymerization. The reaction was continued for $4 \mathrm{~h}$ while keeping the reaction in a nitrogen environment by continuous $\mathrm{N}_{2}$ purging. Following the synthesis, the microgels were purified by three centrifugation cycles at $10,000 \mathrm{rpm}$ for $60 \mathrm{~min}$, with removal of the supernatant and redispersion between each cycle.

Microgel characterization. The thermoresponsive behavior of the resulting pNIPAAmSt microgels was characterized by dynamic light scattering (DLS, Zetasizer Nano instrument from Malvern Instruments Ltd, with the detector positioned at the scattering angle of $173^{\circ}$ ) in the temperature range of $20-50{ }^{\circ} \mathrm{C}$. The microgel dispersion was heated steadily and the microgel size determined every $2{ }^{\circ} \mathrm{C}$ by letting the microgel dispersion equilibrate at each temperature for $10 \mathrm{~min}$. The $\zeta$-potential of the pNIPAAmSt microgels was measured as an indicator of microgel charges using the same Malvern Zetasizer instrument. The sample was prepared in the same way as prepared for size analysis and each mobility value was the average of 100 runs. Transmission Electron Microscopy (TEM, JEM-2100UHR, JEOL) was also used to characterize the dimensions of the microgels. Scanning Electron Microscopy (SEM, S-4800, Hitachi) was used to help examine the microgel patterned surface, with sample surfaces coated with a thin Au layer to increase the contrast and quality of the images. 


\subsection{Patterned pNIPAAmSt microgel strips on cell-adherent surface via negative $\mu \mathrm{CP}$}

Direct utilization of PDMS stamps. The coverslips immersed in PEI solution were rinsed with UHQ water to remove any excess PEI and then dried with nitrogen. The thickness of the PEI polymer layer was $13 \pm 3$ $\mathrm{nm}$, determined by a variable angle spectroscopic ellipsometry (Jobin-Yvon UVISEL). The microgel monolayer was obtained by spin-coating $(1000 \mathrm{rpm}) 1.0 \mathrm{wt} \%$ microgel dispersion onto the PEI-precoated glass coverslips. The fabricated PDMS stamp was first treated with plasma to make the surface hydrophilic, and then put on a cup of hot water to make a thin layer of water to condense on the stamp surface. When the water layer began to evaporate from the edge of the surface, the PDMS stamp was immediately used to contact the microgel film for a few seconds, then the stamp was carefully peeled away, with the patterned strips formed on the coverslip surface.

Indirect utilization of PDMS stamps. The boiling agarose solution (3.5 wt \%) was sonicated to release gas bubbles, and then poured carefully onto the surface of a PDMS stamp. After the cooled agarose hydrogel was peeled away from the PDMS stamp, the agarose stamp with the complementary pattern of the PDMS stamp was formed. It was then dried with $\mathrm{N}_{2}$ to remove any excess moisture on the surface, and then used to make the pNIPAAmSt pattern, with the procedure being just kept the same as that of the PDMS stamp. When the agarose stamp was peeled away, the pNIPAAmSt pattern complementary to that of the PDMS stamp was formed on the coverslip.

The patterns were then immersed in deionized water for $48 \mathrm{~h}$ to release superfluous fluorescent dye, and then the patterns were heated to $120^{\circ} \mathrm{C}$ for $2 \mathrm{~h}$ for sterilization. The morphologies of the patterned surfaces were monitored by inverted fluorescence microscope (Leica, DMI3000, Germany) and scanning electron microscopy (SEM, S-4800, Hitachi). Patterns were named as a-b, with "a" denoting the gap width between the thermoresponsive strips $(\mu \mathrm{m})$ and "b" denoting the width of the microgel strips $(\mu \mathrm{m})$. 


\subsection{Cell culture}

After the glass coverslips with the pNIPAAmSt microgel patterning were annealed at $120{ }^{\circ} \mathrm{C}$ for $2 \mathrm{~h}$, they were transferred into six-well tissue culture plates under sterile conditions for subsequent use. Cells $(2 \times$ $10^{4} / \mathrm{mL}$ ) were seeded uniformly on the coverslips with patterned pNIPAAmSt microgels and cultivated in DMEM medium containing $10 \% \mathrm{FBS}$ at $37{ }^{\circ} \mathrm{C}$ and under $5 \% \mathrm{CO}_{2}$. Unless specified, cell lines used in this work were cultured under the same processes and conditions. All the experiments were undertaken in triplicates and fresh and warm culture medium (preheated to $37{ }^{\circ} \mathrm{C}$ to avoid any possible cell detachment due to temperature drop) was used to replace the old medium every other day. After confluent cell layer formed (3 4 days), cold fresh DMEM was added and the cell detachment process was then observed at ambient temperature (about $20^{\circ} \mathrm{C}$ ) in real time.

\section{Results and discussion}

\subsection{Characterization of pNIPAAmSt microgels}

The pNIPAAmSt microgels produced have a rather compact structural feature with dry size about $200 \mathrm{~nm}$ from TEM imaging (Supporting Information, Figure S1a). The temperature-dependent hydrodiameter of the pNIPAAmSt microgels was analyzed using dynamic light scattering (DLS) (Figure S1b). The polydispersity of the particles was consistently around 0.022 at $20{ }^{\circ} \mathrm{C}$, indicating the narrow particle size distribution achieved using the precipitation polymerization approach. The particles displayed a temperature-dependent size, with an average diameter of $\sim 600 \mathrm{~nm}$ at $20{ }^{\circ} \mathrm{C}$ decreasing to $\sim 270 \mathrm{~nm}$ at $38{ }^{\circ} \mathrm{C}$. The volume phase transition temperature (VPTT) of the pNIPAAmSt microgels was $28{ }^{\circ} \mathrm{C}$, which is lower than that of the pNIPAAm microgels $\left(31 \sim 32{ }^{\circ} \mathrm{C}\right)$ as a result of copolymerization with the hydrophobic monomer styrene. With APS used as initiator, the microgels bear negative charges $\sim-13.3 \mathrm{mV}$ (Figure S1b). 


\subsection{Preparation of patterns}

Microcontact printing $(\mu \mathrm{CP})$ is a typical means of soft lithography and has been successfully applied to patterning various materials ranging from organic molecules, polymers, proteins to nanoparticles and colloids on different substrates. Although $\mu \mathrm{CP}$ has been used to fabricate colloidal microsphere patterns, the physical pressure and temperature between PDMS stamps and substrates are always introduced in the process of $\mu \mathrm{CP}$. In this work, the thermoresponsive microgel patterns were prepared by the negative $\mu \mathrm{CP}$ method based on our previous work. ${ }^{24}$ A monolayer of thermoresponsive microgels was first spin coated on the PEI-precoated glass coverslip. Before use, the PDMS stamp was treated with plasma to make the surface hydrophilic. It was then put over a cup of hot water to condense a thin layer of water on the surface. When the surface was saturated with moisture, the stamp was immediately put in direct contact with the microgel film under the fingertip. After a few seconds, the stamp was carefully peeled away so that the microgels in direct contact with the stamp surface could be lifted off with it. Uncontacted microgels were left to form patterns on the substrate (Figure 1, up line). Note that some boundary areas and patterned objects might not have the exact widths, showing the limitation of this approach. It is however easy to manipulate and reproduce. On the other hand, the complementary pattern could also be prepared using the corresponding agarose stamp (Figure 1, low line). These patterns could be formed in areas about $1 \mathrm{~cm}^{2}$, which are large enough for us to study cell growth and detachment behavior.

SEM images (Figure S2) clearly show that the patterns were composed of microgels. The microgels are not very close-packed, but the gaps between the microgels are similar to what was observed in our previous work and thus have no obvious effect on cell growth and detachment. ${ }^{13}$ Thus for all patterns formed, the gaps between the microgels would not be considered. It should be noted that if the microgel patterns were formed on the bare glass coverslip (without PEI), patterns would be lost in PBS for no longer than 3 days. Thus it is unsuitable for observing cell behavior. With being PEI precoated on the glass coverslip, the 
electrostatic interaction and chain entanglement between microgels and PEI helped anchor the microgels and stabilized the patterns. These patterns could be stable in PBS for at least 7 days (the longest period assessed), though their fluorescent intensity faded away to some extent (Figure S3). This confirms that the pNIPAAmSt microgels deposited on the PEI-precoated coverslip were robust and would not drop off in cell culture media.

\subsection{Cell culture on patterned substrates}

Figure 2 shows an exemplar set of observations of cell attachment and proliferation during the first 3 days after seeding. COS7 cells were first seeded on the 100-100 (denoting gap and microgel strip widths) pNIPAAmSt microgel strips at a density of $2.0 \times 10^{4}$ cells $/ \mathrm{mL}$. The microscopic images of COS7 cells cultured on the microgel patterned coverslip were recorded at different time points in cell culture medium. After $3 \mathrm{~h}$ seeding of the dispersed COS7 cells, cells settled and attached randomly on the whole surface. After $12 \mathrm{~h}$, more cells attached in non-thermoresponsive gaps than on microgel strips. When cultured for 24 $\mathrm{h}$, cells preferentially proliferated within the gaps and cell patterns formed. Then, the COS7 cells proliferated further, forming more clearly patterned cell layers. With culturing time increasing, cells migrated from gaps onto the microgel strips and eventually formed a confluent cell layer on the whole surface (Figure 2).

Figure 3 further shows that COS7 cells could form patterned cell layers after 2 days on surface patterns of 50-100, 100-50 and 200-100, with the first number denoting the gap width in $\mu \mathrm{m}$ and the second number denoting strip width also in $\mu \mathrm{m}$. In our previous work, we showed that NIH3T3 fibroblast cells could be cultured onto the same microgel monolayer to obtain harvestable cell sheets. ${ }^{22}$ However, in this work, we found that COS7 cells preferentially adhered and proliferated on the cell-adherent non-thermoresponsive gaps first to generate patterned cell layers before they start to move onto the thermoresponsive microgel 
strips to form the complete cell monolayer. Thus, cells prefer to adhere and grow on cell-adherent gaps if choices are available. This phenomenon was also found to be true for other cell types such as NIH3T3, 293E, HeLa and L929 cells, as they all preferred to adhere on the PEI-precoated gaps to form patterned cell layers during the early stage of culturing, just as shown in Figure S4.

It is now widely known that cell adhesion relies on the properties of the surface such as hydrophobicity, chemical composition and topography. To investigate whether difference in hydrophobicity between the spacing gap and the strip is responsible for the observed preference in cell adhesion, the strip and gap were further characterized with water contact angle measurements. Since the dimensions of patterned pNIPAAmSt microgel strips and gaps are in micrometer range, then contact angles of the spin coated pNIPAAmSt microgel monolayer and PEI-precoated coverslip were measured to represent those of the patterned pNIPAAmSt microgel strips and gaps. Relative to the PEI-precoated glass coverslip (contact angle lower than $\left.20^{\circ}\right)$, pNIPAAmSt microgels are less hydrophilic both above and below VPTT $\left(32.3 \pm 2.1^{\circ}\right.$ at $20{ }^{\circ} \mathrm{C} ; 68.7 \pm 6.2^{\circ}$ at $38{ }^{\circ} \mathrm{C}$ ). This means that cells prefer to attach and grow on the hydrophilic PEI surface at the early stage.

Tsai et al used pNIPAAm microgels to form patterns on PS substrate via dip coating. ${ }^{17}$ In their work, dense pNIPAAm microgel layers are more hydrophilic than sparsely pNIPAAm microgel coated PS substrates, but they found that NIH3T3 cells would preferably adhere onto the latter. These authors consider that the surface hydrophobicity varied via the pNIPAAm density is likely to be responsible for generating cell micropatterns on dip-coated pNIPAAm microgel substrates, where preferential cell adhesion is observed only on hydrophobic areas immediately after seeding. Yet in this work, COS7 cells preferentially adhered to and spread on hydrophilic PEI coated gaps on glass coverslip. Ishizaki et al. have shown that cells could immediately adhere to the superhydrophilic surfaces in a selective manner after seeding, whereas cells needed $24-72 \mathrm{~h}$ after seeding to adhere to the superhydrophobic surfaces. ${ }^{26}$ The difference in cell 
attachment was attributed to the difference in protein adsorption between the two surfaces, for more time was needed for the cells to produce their own extracellular matrix (ECM) molecules and form a protein layer suitable for cell attachment on the superhydrophobic surface.

The sensitivity of cells to the difference between microgels and PEI-precoated coverslip is so high that cells would even stretch to get into a narrow scratch on the microgel strips (as the red arrow indicated in Figure 3). Taken together, surface hydrophobicity may well be an important factor, but other interactions such as chemical nature and surface topology must also play roles in the dynamic process of cell adhesion. Whilst cells clearly prefer to adhere to the hydrophilic surface, increase in surface density of the microgels appears to deter them. In addition, the more hydrophobic microgel surface is not preferred due to the time lapse needed to produce ECM layer to mediate cell attachment.

Figure 3 also showed clearly that COS7 cells adopted an orientation on the 50-100 patterned surface (the white arrow) where it can be seen that the cells elongated along the direction of the microgel patterns and formed alignment. To quantify the orientation of the spread COS7 cells to the direction of the pattern, the angle between the cell spread direction and the pattern direction was analyzed. The orientation angle was measured as illustrated in Figure $4 \mathrm{a}$. It can range from $0^{\circ}$ to $90^{\circ}$, where $0^{\circ}$ means that the long axis of the cell is parallel to the direction of the pattern and that $90^{\circ}$ represents the orientation that is perpendicular to the pattern direction. Figure $4 \mathrm{~b}$ shows that in the range of about $10^{\circ}$, the cells in the gaps of 50 and $100 \mu \mathrm{m}$ have almost the same alignment orientation angles (69\% and $63 \%$, respectively). They are higher than that of only $36 \%$, in the gap of $200 \mu \mathrm{m}$. These values mean that cells would adopt orientations largely alongside the directions of patterns if the gap widths are not larger than $100 \mu \mathrm{m}$.

\subsection{Cell sheet harvesting by reducing temperature}

After COS7 cells formed a confluent layer on the pNIPAAmSt microgel patterned surface, the detachment 
of the cell sheet was examined against temperature reduction. The cell layer on the patterned surface was first separated from the cells attached on the non-patterned region using a blade. Then, the culture plate was placed under room temperature (about $20^{\circ} \mathrm{C}$ ) for observation without disturbance. Results showed that cell layers could detach from the patterns of 50-100, 50-50, 100-100 and 50-200. However, cell layers could scarcely detach from the patterns of 100-50, 200-50, 200-100 and 500-500 (Figure 5). Live/dead staining assay using calcein-AM and propidium iodide (PI) showed that above 95\% COS7 cells remained alive in the peeled cell sheet (Figure S5a). To further examine the viability, the harvested cell sheet was transferred to a standard TCPS well and cultured. After $24 \mathrm{~h}$, cells could be observed to spread out from the cell sheet (Figure S5b).

Thus, for cells to detach, the width of the thermoresponsive microgel strip must be the same or greater than that of the non-thermoresponsive cell-adherent gap. Provided the cell-cell interaction between COS7 cells is strong enough, the adhesive force between the cell layers and the non-thermoresponsive gaps could be conquered by the detachment force from the thermoresponsive strips. This works well for patterns with strips and gaps below 200. For the pattern of 500-500, the cell layer could not detach spontaneously. It was noted that longer incubation time was required for COS7 cells to get confluent on such a patterned surface. With the widths becoming large, the patterning effects arising from the two opposite surfaces would work differently. To further investigate whether these cell layers could detach from pattern of 200-100 by external force or not, a $100 \mu \mathrm{L}$ pipette tip was used to pipette the culture medium and inject gently against the surface confined cell sheet. Results showed that only the cell layer regions on microgel strips could be detached, whilst the cell layer regions growing in the PEI gaps still remained (Figure S6).

The same set of surface patterns with strips and gaps under $200 \mu \mathrm{m}$ was also used to culture HeLa, NIH3T3 and L929 cells. As described previously, these cells would prefer to proliferate on the gaps, then on the whole surfaces to become confluent, but they could not detach as intact cell sheets by temperature stimuli 
from either thermoresponsive or non-thermoresponsive surface regions spontaneously, though individual cells on the thermoresponsive strips became contracted (Figure 6).

The difference may suggest that COS7 cells have the strongest cell-cell interaction amongst all cell types studied and that this might play an important role in cell sheet recovery process. Cell-cell interactions are clearly important in keeping the integrity of the cell sheet during detachment. In the case of detachment of the co-cultured cell sheet, the strong interacting COS7 cell layer must provide a scaffolding to support the weakly interacting HeLa cell layer so that they can detach simultaneously. To test this assumption, HeLa cells (stained red with DiD) were first seeded on the pattern 100-100. Once HeLa cells formed patterned cell layers in the gaps, COS7 cells (stained green with DiO) were seeded as the second type of cells. When confluent cell layers were formed on the whole surface, warm culture medium was replaced by cold culture medium to stimulate detachment. Results showed that the entire cell sheet containing both COS7 and HeLa cell sheet could detach from the surface as a whole entity (Figure 7). Thus, by harnessing the strong cell-cell interactions, patterned cell sheets may be recovered using this platform through manipulating the repulsive and attractive interactions against the substrates via the width of the patterned strips. Patterned cell sheets can be used as building units for constructing cell spheroids as tumor tissue models for testing the efficacy of anti-cancer drugs.

\section{Conclusion and outlook}

In this study, we developed a simple microcontact printing technique to fabricate patterned thermoresponsive microgel strips with various widths and gaps on non-thermoresponsive cell-adherent surface. These patterned surfaces were then used to investigate how the critical widths of strip and gap affected COS7 fibroblast cell sheet recovery. It was found that COS7 cells could preferentially attach and proliferate in the gaps between the microgel strips to form patterned cell layers during the early stage of 
culturing. The cells then migrated from the PEI-coated gaps to the microgel strips to form a confluent cell layer. These COS7 cell sheets could be recovered when the width of the thermoresponsive strip is not narrower than that of the non-thermoresponsive cell-adherent gap, and the detachment did not appear to damage the cells and patterns. Other cells such as 3T3 fibroblast, HeLa and L929 cells grew on these patterned surfaces similarly, but cell sheets could not be harvested due to the lack of strength within them. However, co-culturing of COS7 and HeLa cells could lead to the successful detachment again due to the strength of the COS7 cells in the patterned cell layer. Thus, these surface patterns can work as a platform for harvesting co-cultured cell sheets, useful for building functional tissue constructs such as tumor models.

\section{Associated content}

The Supporting Information including the TEM image of the microgel, SEM image of pattern of 50-50, Fluorescent and bright-field images of patterns, Different cell types adhered on patterns, Live/dead fluorescent staining of a freshly detached COS7 cell sheet from pattern 100-100 and COS7 cell layer formed on pattern 200-100 is available free of charge via the Internet at http://pubs.acs.org.

\section{Acknowledgments}

The authors gratefully acknowledge the financial support from the Natural Science Fund of Shandong Province (ZR2015BM013), the Fundamental Research-Funds for the Central Universities (14CX02121A, 15CX05017A) and the UK Physical Science and Engineering Research Council (EPSRC, EP/F062966/1) and Innovate UK (KTP008143) for support. 


\section{References}

1. Purrucker, O.; Förtig, A.; Lüdtke, K.; Jordan, R.; Tanaka, M. Confinement of Transmembrane Cell Receptors in Tunable Stripe Micropatterns. J. Am. Chem. Soc. 2005, 127, 1258-1264.

2. Amschler, K.; Erpenbeck, L.; Kruss, S.; Schön, M. P. Nanoscale Integrin Ligand Patterns Determine Melanoma Cell Behavior. ACS Nano. 2014, 8, 9113-9125.

3. Kolodziej, C. M.; Kim, S. H.; Broyer, R. M.; Saxer, S. S.; Decker, C. G.; Maynard, H. D. Combination of Integrin-Binding Peptide and Growth Factor Promotes Cell Adhesion on Electron-Beam-Fabricated Patterns. J. Am. Chem. Soc. 2012, 134, 247-255.

4. Yao, X.; Peng, R.; Ding, J. Cell-Material Interactions Revealed via Material Techniques of Surface Patterning. Adv. Mater. 2013, 25, 5257-5286.

5. Kilian, K. A.; Bugarija, B.; Lahn, B. T.; Mrksich, M. Geometric Cues for Directing the Differentiation of Mesenchymal Stem Cells. Proc. Natl. Acad. Sci. U. S. A. 2010, 107, 4872-4877.

6. Chen, C. S.; Mrksich, M.; Huang, S.; Whitesides, G. M.; Ingber, D. E. Geometric Control of Cell Life and Death. Science 1997, 276, 1425-1428.

7. McBeath, R.; Pirone, D. M.; Nelson, C. M.; Bhadriraju, K.; Chen, C. S. Cell Shape, Cytoskeletal Tension, and rhoA Regulate Stem Cell Lineage Commitment. Dev. Cell 2004, 6, 483-495.

8. Hoesli, C. A.; Garnier, A.; Juneau, P. M.; Chevallier, P.; Duchesne, C.; Laroche, G. A Fluorophore-Tagged RGD Peptide to Control Endothelial Cell Adhesion to Micropatterned Surfaces. Biomaterials 2014, 35, 879-890.

9. Rianna, C.; Ventre, M.; Cavalli, S.; Radmacher, M.; Netti, P. A. Micropatterned Azopolymer Surfaces Modulate Cell Mechanics and Cytoskeleton Structure. ACS Appl. Mater. Interfaces 2015, 7, $21503-$ 
10. Hong, Y.; Yu, M.; Weng, W.; Cheng, K.; Wang, H.; Lin, J. Light-Induced Cell Detachment for Cell Sheet Technology. Biomaterials 2013, 34, 11-18.

11. Zahn, R.; Thomasson, E.; Guillaume-Gentil, O.; Vörös, J.; Zambelli, T. Ion-Induced Cell Sheet Detachment from Standard Cell Culture Surfaces Coated with Polyelectrolytes. Biomaterials 2012, 33, 3421-3427.

12. Pan, G.; Guo, Q.; Ma, Y.; Yang, H.; Li, B. Thermo-Responsive Hydrogel Layers Imprinted with RGDS Peptide: A System for Harvesting Cell Sheets. Angew. Chem. Int. Edit. 2013, 52, 6907-6911.

13. Xia, Y.; He, X.; Cao, M.; Wang, X.; Sun, Y.; He, H.; Xu, H.; Lu, J. R. Self-Assembled Two-Dimensional Thermoresponsive Microgel Arrays for Cell Growth/Detachment Control. Biomacromolecules 2014, 15, 4021-4031.

14. Kim, H.D.; Heo, J.S.; Park, T.; Park, C.; Kim, H.O.; Kim, E. Photothermally Induced Local Dissociation of Collagens for Harvesting of Cell Sheets. Angew. Chem. Int. Edit. 2015, 127, 5967-5971.

15. Takahashi, H.; Nakayama, M.; Itoga, K.; Yamato, M.; Okano, T. Micropatterned Thermoresponsive Polymer Brush Surfaces for Fabricating Cell Sheets with Well-Controlled Orientational Structures. Biomacromolecules 2011, 12, 1414-1418.

16. Tsai, H.-Y.; Vats, K.; Yates, M.Z.; Benoit, D.S.W. Two-Dimensional Patterns of Poly (N-isopropylacrylamide) Microgels to Spatially Control Fibroblast Adhesion and Temperature-Responsive Detachment. Langmuir 2013, 29, 12183-12193.

17. Tanaka, N.; Ota, H.; Fukumori, K.; Miyake, J.; Yamato, M.; Okano, T. Micro-Patterned Cell-Sheets Fabricated with Stamping-Force-Controlled Micro-Contact Printing. Biomaterials 2014, 35, 9802-9810.

18. Kumashiro, Y.; Matsunaga, T.; Muraoka, M.; Tanaka, N.; Itoga, K.; Kobayashi, J.; Tomiyama, Y.; Kuroda, M.; Shimizu, T.; Hashimoto, I.; Umemura, K.; Yamato, M.; Okano, T. Rate Control of Cell 
Sheet Recovery by Incorporating Hydrophilic Pattern in Thermoresponsive Cell Culture Dish. $J$. Biomed. Mater. Res. A. 2014, 102, 2849-2856.

19. Ricoult, S. G.; Sanati Nezhad, A.; Knapp-Mohammady, M.; Kennedy, T. E.; Juncker, D. Humidified Microcontact Printing of Proteins: Universal Patterning of Proteins on Both Low and High Energy Surfaces. Langmuir 2014, 30, 12002-12010.

20. Lange, S. A.; Benes, V.; Kern, D. P.; Hörber, J. K. H.; Bernard, A. Microcontact Printing of DNA Molecules. Anal. Chem. 2004, 76, 1641-1647.

21. Xu, L.; Robert, L.; Ouyang, Q.; Taddei, F.; Chen, Y.; Lindner, A. B.; Baigl, D. Microcontact Printing of Lving Bacteria Arrays with Cellular Resolution. Nano Lett. 2007, 7, 2068-2072.

22. Santhanam, V.; Andres, R. P. Microcontact Printing of Uniform Nanoparticle Arrays. Nano Lett. 2004, $4,41-44$

23. Yan, X.; Yao, J.; Lu, G.; Chen, X.; Zhang, K.; Yang, B. Microcontact Printing of Colloidal Crystals. J. Am. Chem. Soc. 2004, 126, 10510-10511.

24. Xia, Y.; Tang, Y.; He, X.; Pan, F.; Li, Z.; Xu, H.;Lu, J. R. Patterned Thermoresponsive Microgel Surfaces to Control Cell Detachment. Biomacromolecules 2016, 17, 572-579.

25. Xia, Y.; He, X.; Cao, M.; Chen, C.; Xu, H.; Pan, F.; Lu, J. R. Thermoresponsive Microgel Films for Harvesting Cells and Cell Sheets. Biomacromolecules 2013, 14, 3615-3625.

26. Ishizaki, T.; Saito, N.; Takai, O. Correlation of Cell Adhesive Behaviors on Superhydrophobic, Superhydrophilic, and Micropatterned Superhydrophobic/Superhydrophilic Surfaces to Their Surface. Langmuir 2010, 26, 8147-8154. 


\section{Figure captions}

Figure 1. Fluorescent and bright-field images of representative patterns of 50-50, 100-50, 100-100, 200-100, 200-50 and 500-500 prepared by PDMS stamps (up line); patterns of 50-50, 50-100, 100-100, 100-200, 50-200 and 500-500 prepared by agarose stamps (low line). The first number means the width of the cell-adhesion region and the second number means the width of the thermoresponsive microgel region.

Figure 2. Time-lapse microscopic images of adhesion, migration and proliferation of COS7 cells on pattern 100-100 with different incubation times. The scale bars is $100 \mu \mathrm{m}$.

Figure 3. Microscopic images illustrate that on patterns of 50-100, 100-50 and 200-100, COS7 cells preferred to adhere and proliferate inside the gaps. The scale bar is $100 \mu \mathrm{m}$.

Figure 4. (a) Schematic to show the measurements of the cell orientation angles; (b) Orientation angle frequency distribution of cells cultured on patterns of 50-100, 100-50 and 200-100 after $48 \mathrm{~h} .100$ cells in total were measured on each pattern.

Figure 5. Detachment behavior of COS7 cell layers on different patterns. The cell culture medium was first replaced with cold fresh medium $\left(4{ }^{\circ} \mathrm{C}\right)$, and then placed at room temperature (about $20{ }^{\circ} \mathrm{C}$ ) for observation without disturbance. Cell layer detached from patterns of 50-100, 50-50, 100-100 and 50-200, but could not detach from patterns of 100-50, 200-50, 200-100 and 500-500.

Figure 6. Detachment behavior from other types of cell layers on 100-100 pattern. The cell culture medium was first replaced with cold fresh medium $\left(4{ }^{\circ} \mathrm{C}\right.$ ), and then placed at room temperature (about $20{ }^{\circ} \mathrm{C}$ ) for 
observation without disturbance. (a) NIH3T3 cell layer; (b) L929 cell layer and (c) HeLa cell layer. The scale bar is $100 \mu \mathrm{m}$.

Figure 7. The procedure to grow and harvest patterned HeLa (red) and COS7 (green) cell sheets by sequential co-culturing from 100-100 pNIPAAmSt microgel strips. The scale bar is $100 \mu \mathrm{m}$. 


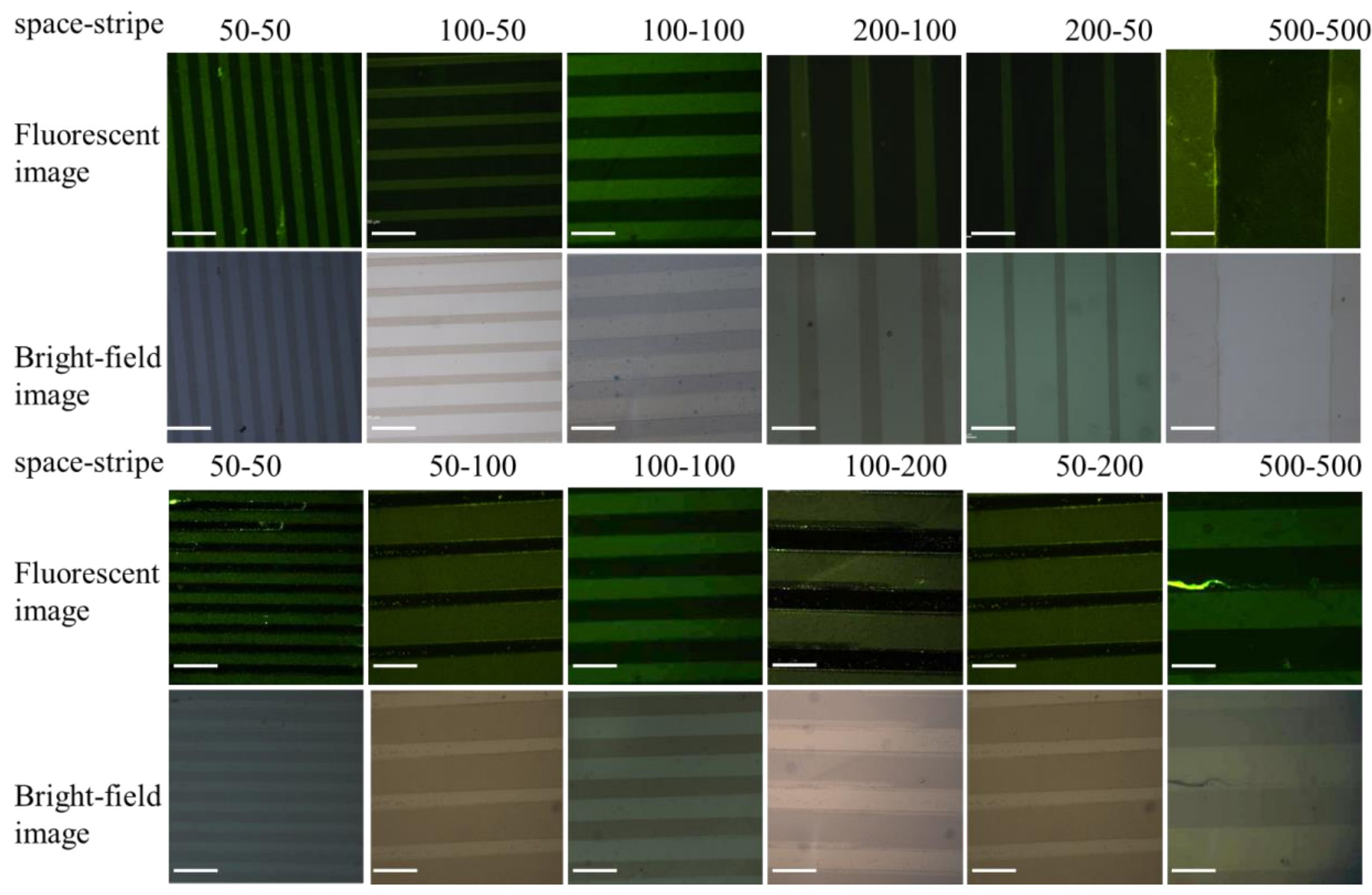

Figure 1 

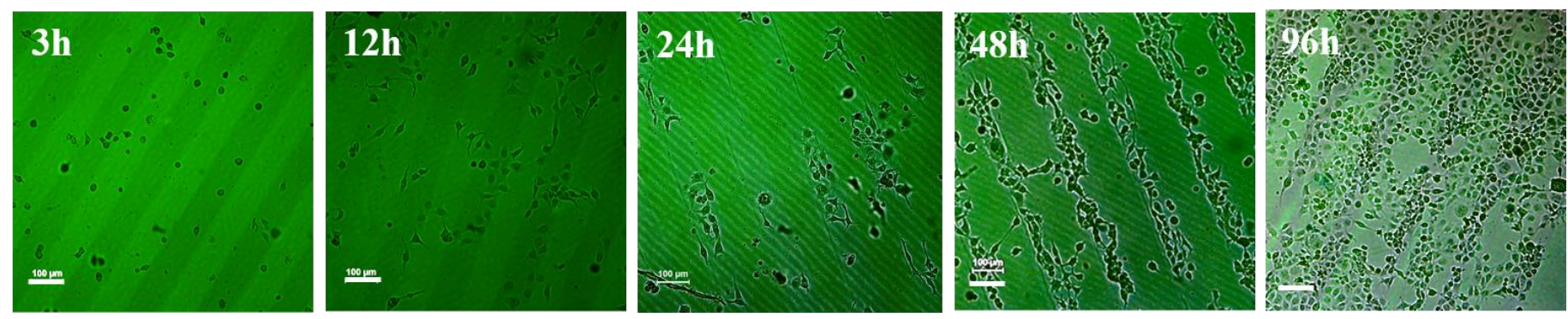

Figure 2 
patterns of microgel
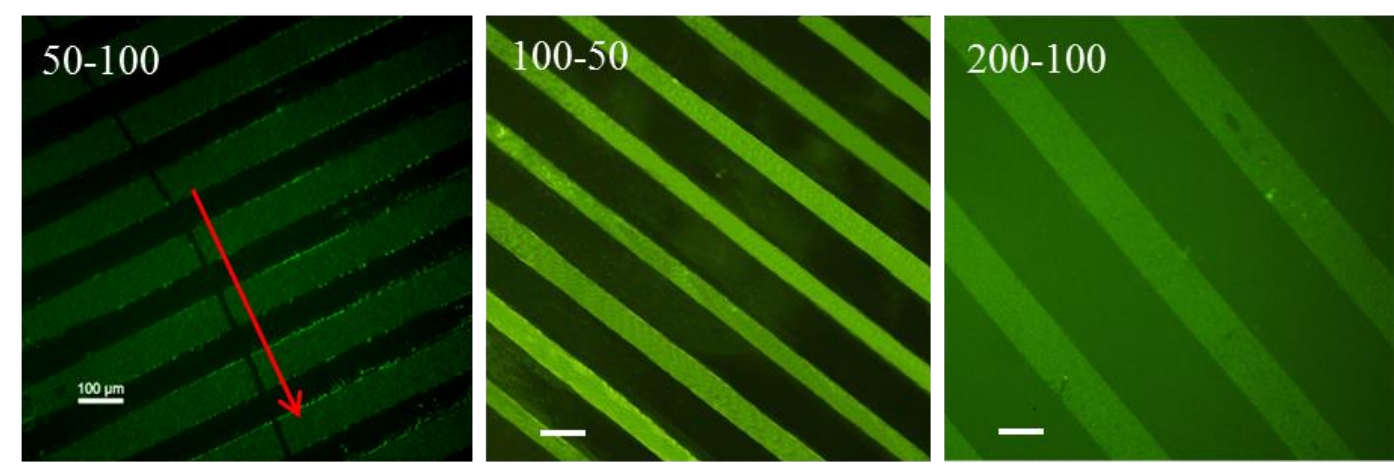

cell culture on surface
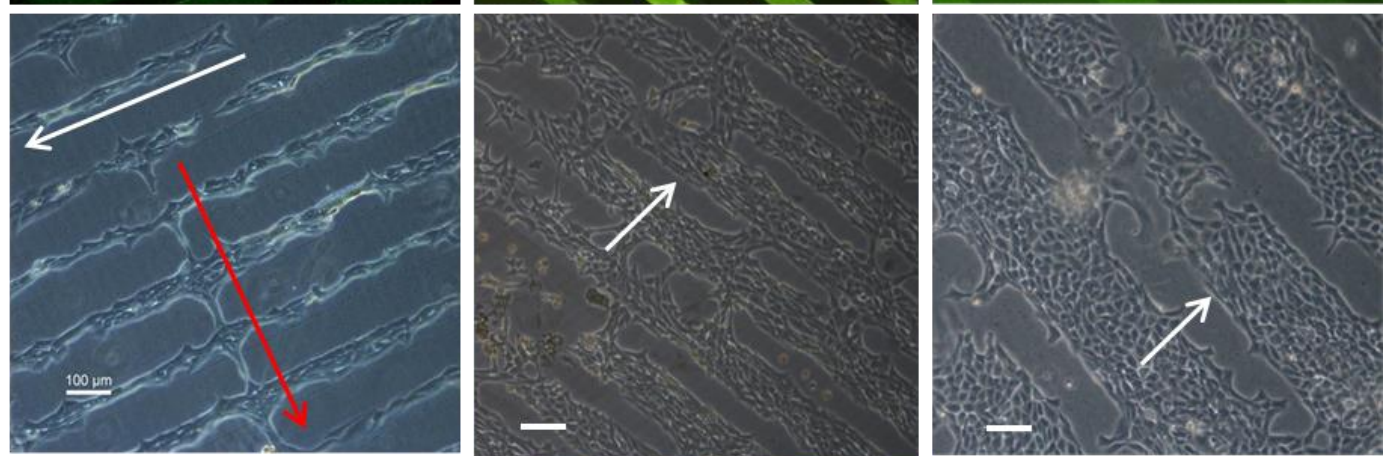

overlay
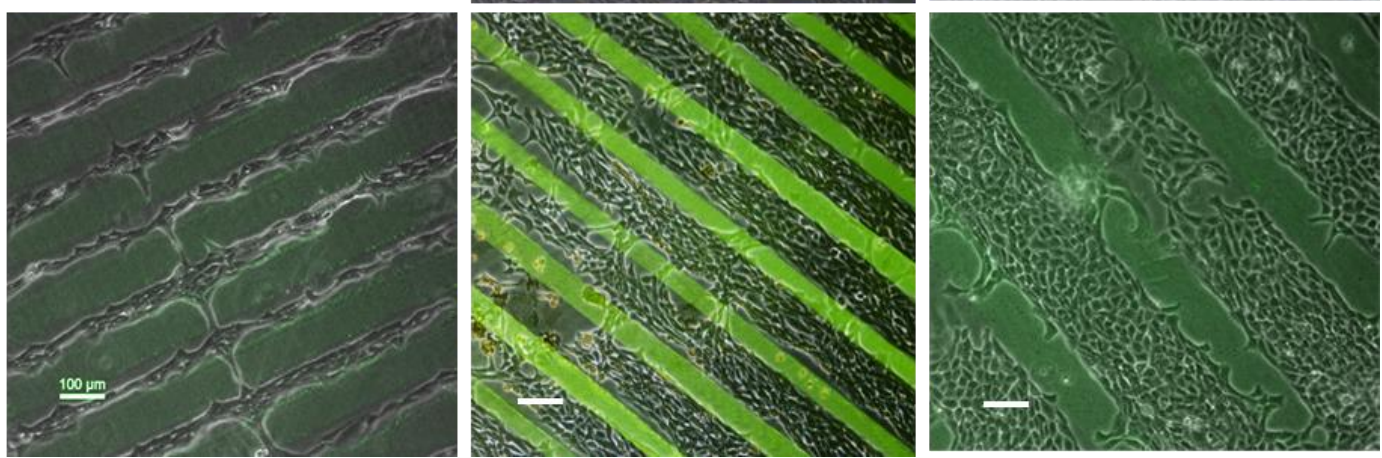

Figure 3 
a

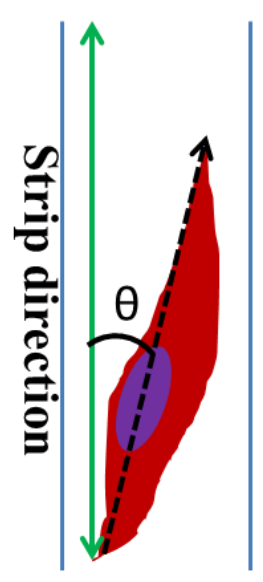

b

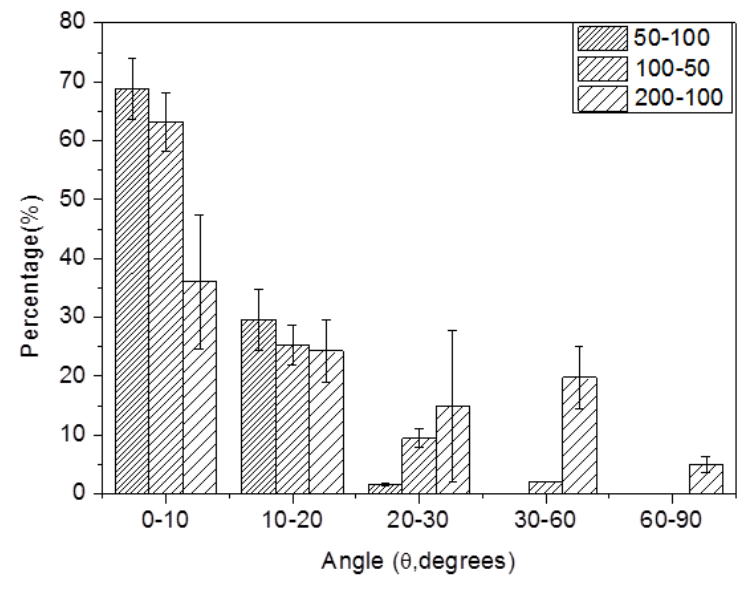

Figure 4 


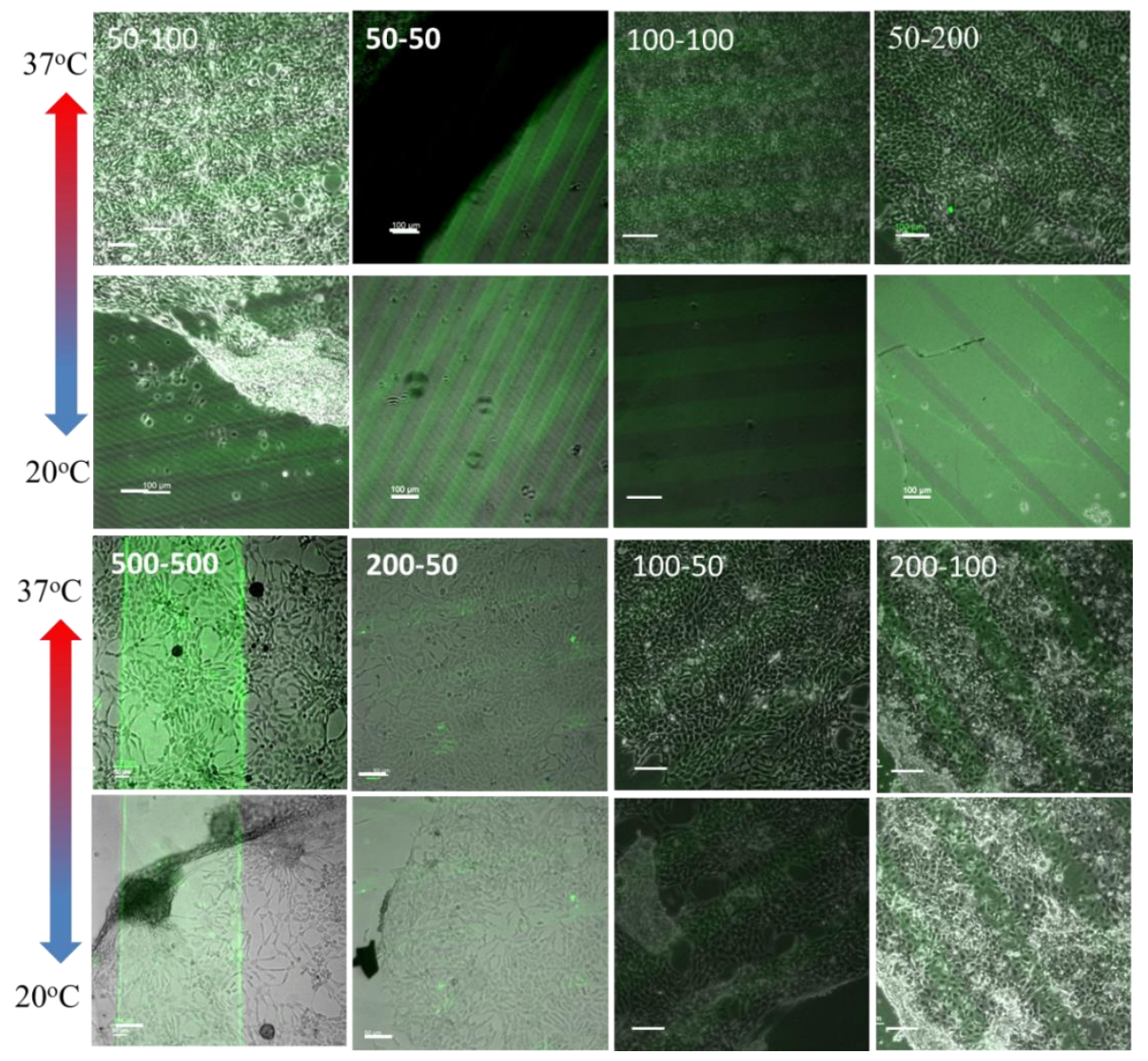

Figure 5 


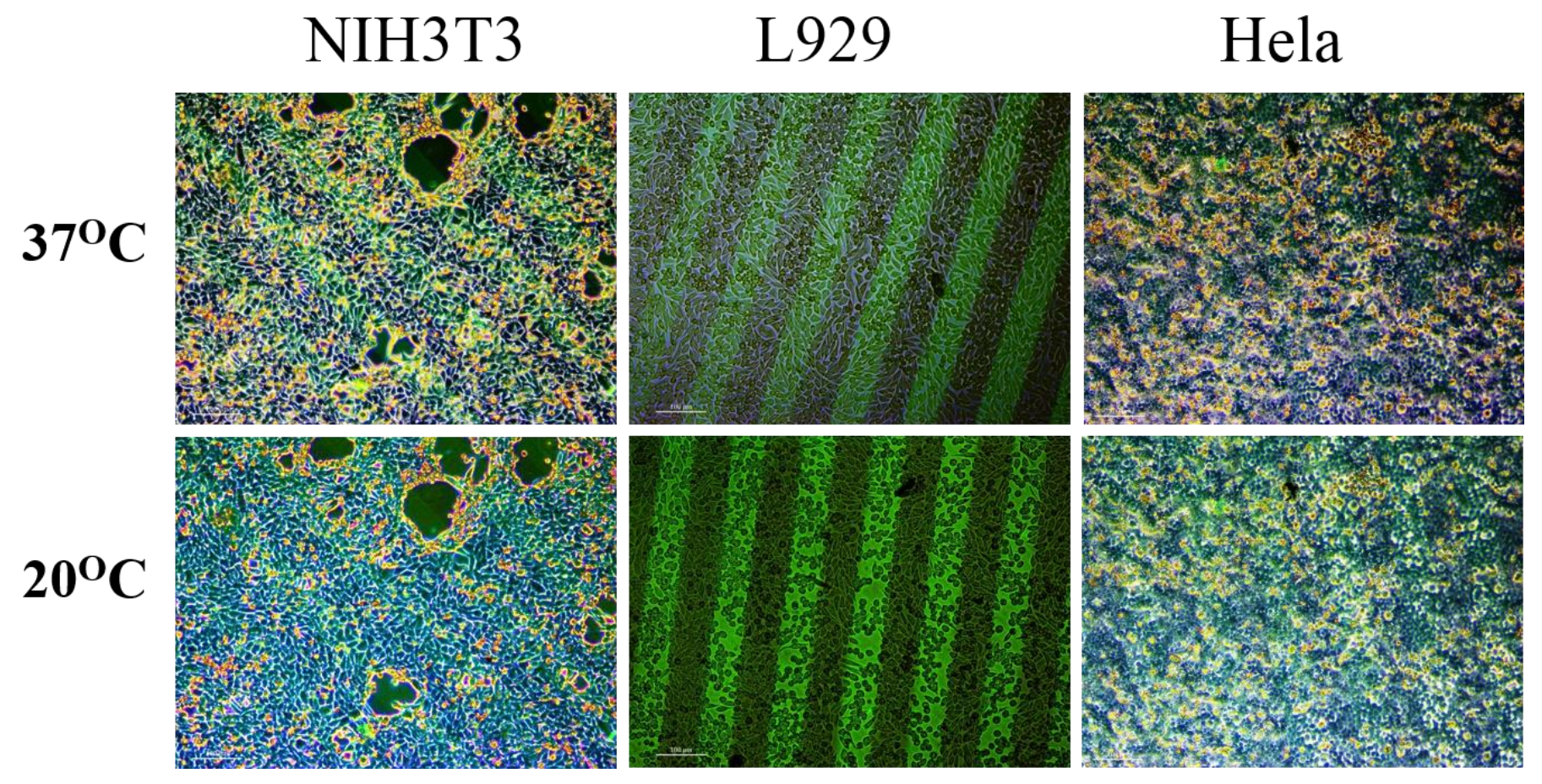

Figure 6 


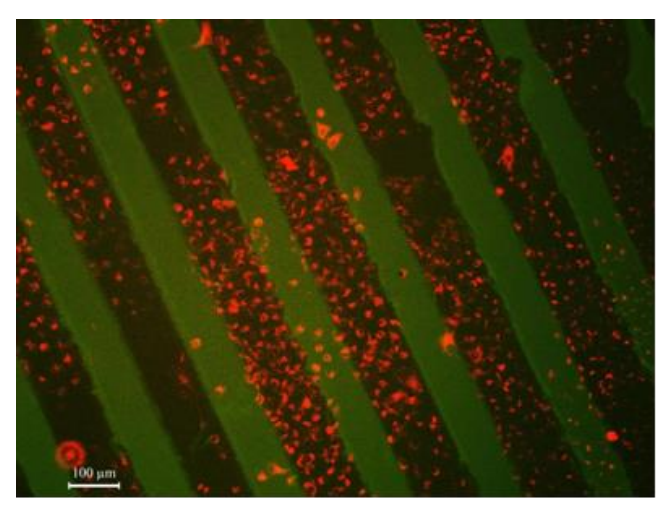

HeLa cells first seeded

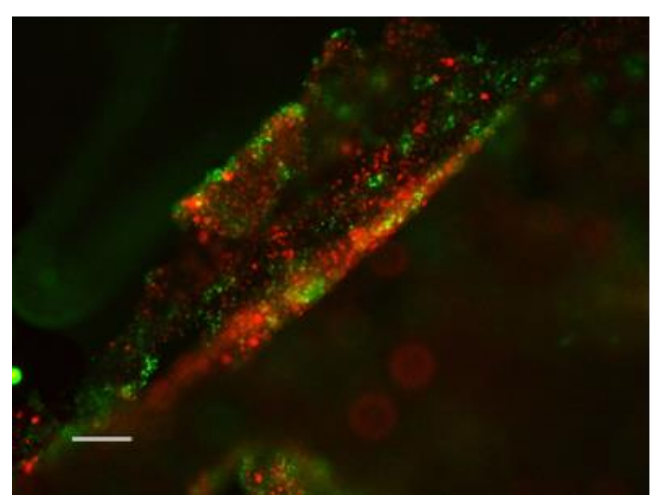

\section{COS7 cells second seeded}

Patterned cell sheets

Figure 7
Patterned cell layers

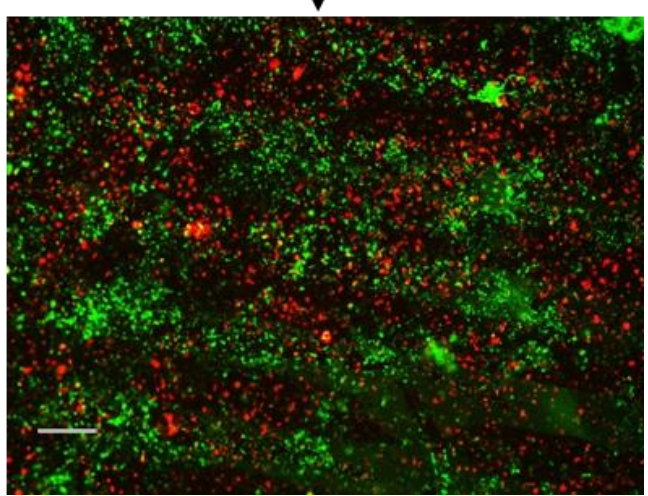




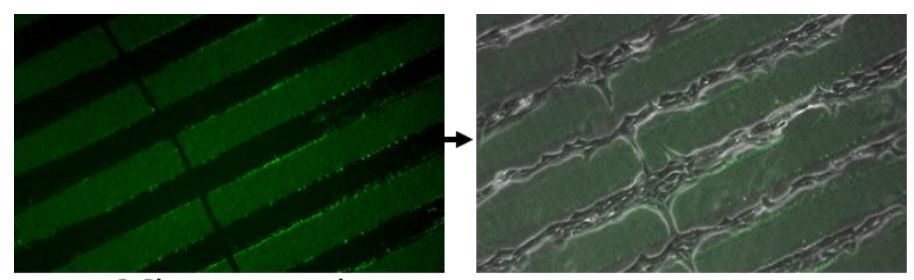

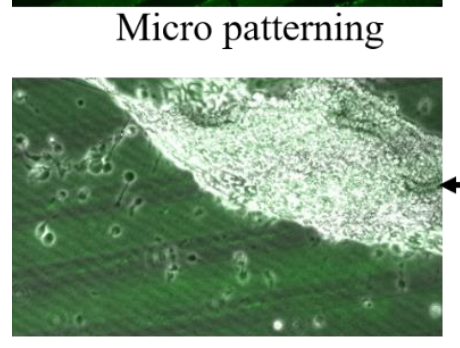

Thermal detachment
Attachment and spreading

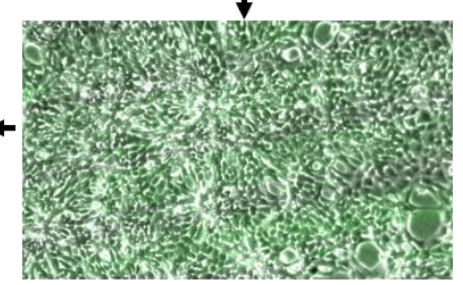

Further growth 